\title{
FOTOPRODUKSI MESON-ETA PADA PROTON
}

\author{
Alhidayatuddiniyah T.W. \\ Program Studi Informatika, Universitas Indraprasta PGRI \\ alhida.dini@gmail.com
}

\begin{abstract}
Abstrak
Telah diinvestigasi reaksi fotoproduksi $\gamma p \rightarrow \eta p$ dengan tujuan menghitung hasil fotoproduksi meson-eta pada proton dengan menggunakan model isobar untuk menghasilkan data numerik yang sesuai dengan data eksperimen. Amplitudo transisi pada kerangka pusat massa dijabarkan ke dalam amplitudo Chew-Goldberger-Low-Nambu (CGLN). Amplitudo yang ditinjau melibatkan kanal-s, -t, dan -u pada suku Born dan resonans. Reaksi fotoproduksi $\gamma p \rightarrow \eta p$ dikembangkan dengan model isobar. Kontribusi dari masing-masing kanal berdasarkan formulasi polarisasi foton dan penampang lintang differensial. Parameter model ditentukan melalui fitting dengan data eksperimen. Diperoleh hasil, bahwa model ini belum cukup baik dalam menghasilkan data numerik yang sesuai dengan data eksperimen, sehingga diperlukan studi lanjut untuk mem-fitting data eksperimen dan memasukkan faktor bentuk ke dalam model agar diperoleh nilai-nilai parameter yang ada di dalam model.
\end{abstract}

Kata Kunci : fotoproduksi, meson- $\eta$, amplitudo CGLN, polarisasi, penampang lintang differensial.

\begin{abstract}
This research is aimed at calculating the results of eta-meson photoproduction on protons using an isobar model to produce numerical data corresponding to the experimental data by investigating the reaction of photoproduction $\gamma p \rightarrow \eta p$.. The amplitude transitions at the center of mass frame are translated into amplitude of Chew-Goldberger-Low-Nambu (CGLN). The amplitude of the terms involving the channel-s, -t, and $-u$ in Born term and Resonans term. The reaction of photoproduction $\gamma p \rightarrow \eta p i s$ developed using isobaric models. Formulated also the differential cross section and polarization of photons to see the contribution of each channel. Model parameters are determined by fitting the experimental data. The result is this model is not good enough to produce numerical data in accordance with the experimental data.So, further study is needed to fit the experimental data and substitute the form factor into the model in order to obtain the parameter values present in the model.
\end{abstract}

Keywords : photoproduction, meson- $\eta$, CGLN-amplitude, polarization, differential cross section.

\section{PENDAHULUAN}

\section{A. Latar Belakang}

Fotoproduksi merupakan reaksi antara foton dengan suatu partikel yang menghasilkan partikel lain diakhir reaksi.

Pada model isobar $\gamma, \eta$, dan proton sudah dianggap partikel elementer tanpa memperhitungkan quark. Model ini merupakan salah satu cara menjelaskan fenomena sub-atomik. Reaksi fotoproduksi $\eta$ meson adalah salah satu contoh fotoproduksi untuk spektroskopi baryon dengan isospin 0 . Reaksi ini menghasilkan sebuah "isospin filter" pada spektrum resonan baryon. Filter isospin ini mengeliminasi banyak state sehingga membuat tingkat eksitasi nukleon lebih sederhana [4].

Penyelidikan fotoproduksi $\eta$ memberikan kemungkinan pencarian resonansiresonansi yang hilang (missing resonaces), yang tidak dapat diobservasi dalam hamburan $\pi \mathrm{N}$ dan fotoproduksi $\pi$ pada nukleon. Fotoproduksi $\eta$ pada proton memberikan sebuah kesempatan unik untuk mempelajari properties dari resonan $S_{11}$ (1535) karena resonan ini memiliki sebuah ratio cabang yang lebar ke dalam kanal $\eta p .[1]$.

Berdasarkan hal tersebut, maka penelitian ini dibatasi pada kajian teori mengenai reaksi fotoproduksi meson $\eta$ pada proton 
dengan menggunakan model isobar dan formalisme amplitudo transversal pada kerangka pusat massa yang dijabarkan ke dalam amplitudo Chew-Goldberger-LowNambu (CGLN). Dengan menggunakan resonan $S_{11}$ (1535) serta perhitungan observabel yang diteliti yaitu penampang lintang differensial dan polarisasi foton dengan energi foton Lab. yang digunakan $875 \mathrm{MeV}, 925 \mathrm{MeV}, 975 \mathrm{MeV}$, dan 1025 $\mathrm{MeV}$.

\section{B. Tujuan Penelitian}

Tujuan dari penelitian ini, yaitu menghitung hasil fotoproduksi meson-eta pada proton dengan menggunakan model isobar untuk menghasilkan data numerik yang sesuai dengan data eksperimen.

\section{Manfaat Penelitian}

Manfaat penelitian ini, yaitu mendapatkan hasil keakurasian model yang digunakan dalam memproduksi data secara teoritik (model isobar) terhadap data hasil eksperimen dan formulasi yang sesuai, dengan menjabarkan amplitudo transisi pada kerangka P.M. ke dalam amplitudo CGLN.

\section{Kajian Teori}

\section{Model Standar}

Model standar mencakup pembahasan partikel elementer pembentuk materi, yaitu quark dan lepton. Quark selalu berada bersama dengan sebuah antiquark sehingga membentuk meson atau bersama dengan quark lainnya membentuk baryon[7].

Eta termasuk golongan meson karena merupakan gabungan dari sebuah quark dan antiquark. Dengan massa diamnya $547.862 \pm 0.018 \mathrm{MeV} / \mathrm{c}^{2}$.

\begin{tabular}{lcccccccccc}
\hline \hline Flavour & Simbol & Massa $\left(\mathrm{MeV} / c^{2}\right)$ & $J^{P}$ & $B^{\prime}$ & $Q$ & $I_{z}$ & $C$ & $S$ & $T$ & $B$ \\
\hline up & $\mathrm{u}$ & $1.7-3.1$ & $+\frac{1}{2}$ & $+\frac{1}{3}$ & $+\frac{2}{3}$ & $+\frac{1}{2}$ & 0 & 0 & 0 & 0 \\
down & $\mathrm{d}$ & $4.1-5.7$ & $+\frac{1}{2}$ & $+\frac{1}{3}$ & $-\frac{1}{3}$ & $-\frac{1}{2}$ & 0 & 0 & 0 & 0 \\
charm & $\mathrm{c}$ & $1290_{-110}^{+50}$ & $+\frac{1}{2}$ & $+\frac{1}{3}$ & $+\frac{2}{3}$ & 0 & +1 & 0 & 0 & 0 \\
strange & $\mathrm{s}$ & $100_{-20}^{+30}$ & $+\frac{1}{2}$ & $+\frac{1}{3}$ & $-\frac{1}{3}$ & 0 & 0 & -1 & 0 & 0 \\
top & $\mathrm{t}$ & $172900 \pm 600 \pm 900$ & $+\frac{1}{2}$ & $+\frac{1}{3}$ & $+\frac{2}{3}$ & 0 & 0 & 0 & +1 & 0 \\
bottom & $\mathrm{b}$ & $4190_{-60}^{+180}$ & $+\frac{1}{2}$ & $+\frac{1}{3}$ & $-\frac{1}{3}$ & 0 & 0 & 0 & 0 & -1 \\
\hline \hline
\end{tabular}

Gambar 1. Enam generasi quark beserta sifatsifatnya. Keterangan $J^{P}$ : momentum angular total, $B$ ': bilangan baryon, $Q$ : muatan listrik, $I z$ : isospin, $C$ : charm, $S$ : strangeness, $T$ : topness, $B$ : bottomness. Data ini berdasarkan Particle Data Group [9]

\section{Kinematika Relativistik}

a. Momentum-4 dan Variabel Mandelstam Pada penelitian ini, proses perhitungan pada reaksi fotoproduksi menggunakan kinematika relativistik, karena energi yang digunakan jauh lebih besar dibandingkan dengan massa partikel yang berinteraksi $(E>>m)$. Persamaan reaksi umum yang bersesuaian dengan penelitian adalah

$$
\gamma(k)+p\left(p_{1}\right) \rightarrow \eta(q)+p\left(p_{2}\right)
$$

Momentum-4 dari partikel yang saling bereaksi dituliskan sebagai berikut:

$$
\begin{gathered}
k=\left\{E_{\gamma}, \vec{k}\right\}=\left\{k_{0}, \vec{k}\right\} \\
P_{1}=\left\{E_{1}, \overrightarrow{P_{1}}\right\} \\
q=\left\{E_{\eta}, \vec{q}\right\}(4) \\
P_{2}=\left\{E_{2}, \overrightarrow{P_{2}}\right\}
\end{gathered}
$$

dan momentum-4 pada kerangka Lab-nya, yaitu:

$$
\begin{aligned}
& k=\left\{\tilde{E}_{\gamma}, \tilde{\vec{\kappa}}\right\}=\left\{\tilde{k}_{0}, \tilde{\vec{\kappa}}\right\} \\
& P_{1}=\left\{m_{P}, 0\right\} \\
& q=\left\{\tilde{E}_{\eta}, \tilde{\vec{q}}\right\} \\
& P_{2}=\left\{\tilde{E}_{2}, \widetilde{P_{2}}\right\}
\end{aligned}
$$

Sedangkan pada kerangka P.M. sebagai berikut:

$$
\begin{aligned}
& k=\left\{E_{\gamma}, \vec{k}\right\}=\left\{k_{0}, \vec{k}\right\} \\
& P_{1}=\left\{E_{1},-\vec{k}\right\} \\
& q=\left\{E_{\eta}, \vec{q}\right\} \\
& P_{2}=\left\{E_{2},-\vec{q}\right\}
\end{aligned}
$$


Tanda tilde digunakan untuk membedakan momentum,-4 di kerangka Lab dengan momentum-4 di kerangka P.M..

\section{b. Momentum-3 dalam Kerangka Pusat Massa}

Momentum partikel foton dalam kerangka pusat massa, yaitu:

$\left|\vec{P}_{\gamma}\right|=|\vec{k}|=$

$\sqrt{\frac{\left[W^{2}-\left(m_{\gamma}+m_{P}\right)^{2}\right]\left[W^{2}-\left(m_{\gamma}-m_{P}\right)^{2}\right]}{4 W^{2}}}$

Sedangkan momentum partikel $\eta$ dalam kerangka pusat massa, yaitu:

$\left|\vec{P}_{\eta}\right|=\sqrt{\frac{\left[W^{2}-\left(m_{\eta}+m_{P}\right)^{2}\right]\left[W^{2}-\left(m_{\eta}-m_{P}\right)^{2}\right]}{4 W^{2}}}$

\section{c. Energi Ambang}

Energi ambang foton pada kerangka Lab. yaitu:

$$
E_{\gamma}=|\tilde{k}|^{t h}=\frac{W^{2}-m_{P}^{2}}{2 m_{P}}
$$

dan energi ambang foton pada kerangka P.M., yaitu:

$$
|\tilde{k}|^{t h}=\frac{m_{\eta}^{2}+2 m_{\eta} m_{P}}{2\left(m_{\eta}+m_{P}\right)}
$$

dengan mensubstitusikan, $m_{\eta}=$ $547.3 \mathrm{MeV}$ dan $m_{P}=938.272 \mathrm{MeV}$, maka energi ambang fotonnya adalah : $|\tilde{k}|^{\text {th }}=706,92 \mathrm{MeV}$.

\section{d. Fotoproduksi Eta Pada Proton}

Fotoproduksi eta pada proton didefinisikan sebagai reaksi antara foton dan proton yang menghasilkan eta serta proton, $\gamma \mathrm{p} \rightarrow \eta \mathrm{p}$, yang dalam hal ini dengan menggunakan model isobar. Model isobar merupakan model yang dibangun beradasarkan diagram Feynman untuk masing-masing kanal-s, kanal-t, dan kanal$\mathrm{u}$, baik untuk suku born ataupun resonans. Model isobar memperlakukan setiap partikel yang terlibat seperti partikel titik, dimana tidak mempertimbangkan komposisi quark yang membentuk partikel tersebut.
Salah satu kelemahan model isobarik adalah pada umumnya amplitudo hamburan menjadi besar sekali (divergen) pada energi yang makin besar. Pada umumnya teknik yang digunakan untuk mengatasi permasalahan ini adalah memasukkan faktor bentuk hadronik pada verteks hadronik dari diagram Feynman [10].

Berikut ini diagram feynman yang digunakan pada fotoproduksi eta meson pada proton:
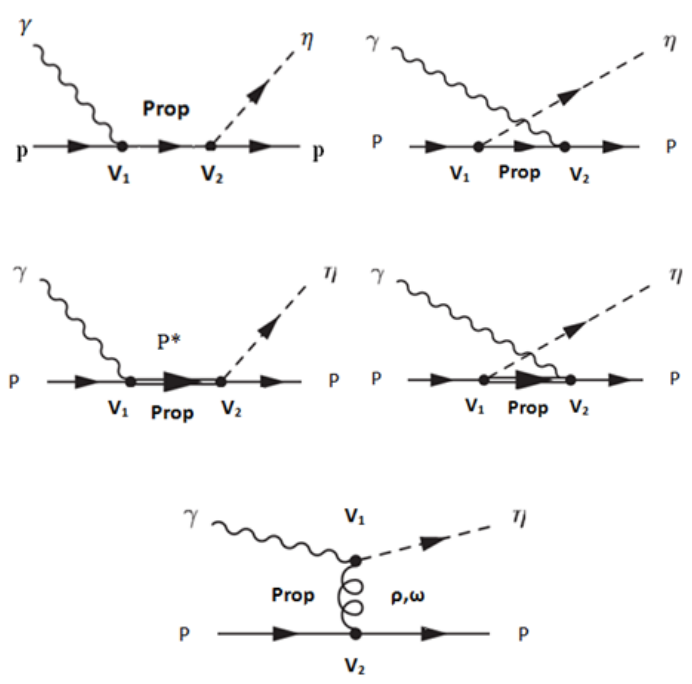

Gambar 2. Diagram feynman fotoproduksi eta meson pada proton

Verteks dan propagator yang digunakan dalam penelitian ini, yaitu:

\begin{tabular}{lc}
\hline \hline Verteks & Kopling \\
\hline$\eta p p$ & $g_{\eta p p} \gamma^{5}$ \\
$\eta p p^{*}\left(\frac{1}{2}^{+}\right)$ & $g_{\eta p p^{*}} \gamma^{5}$ \\
$\eta p p^{*}\left(\frac{1}{2}^{-}\right)$ & $-i g_{\eta p p^{*}} \gamma^{5}$ \\
\hline \hline
\end{tabular}

Gambar 3. Konstanta kopling hadron 


\begin{tabular}{cc}
\hline \hline Verteks & Propagator \\
\hline spin 0 & $\frac{i}{q^{2}-m^{2}+i m \Gamma}$ \\
$\operatorname{spin} \frac{1}{2}$ & $\frac{i(q+m)}{q^{2}-m^{2}+i m \Gamma}$ \\
$\operatorname{spin} 1$ & $\frac{i}{q^{2}-m^{2}+i m \Gamma}\left(-g_{\mu v}+\frac{q_{\mu} q_{v}}{m^{2}}\right)$ \\
\hline \hline
\end{tabular}

Gambar 4. Propagator untuk partikel dengan momentum $q$ dan massa $m$

\begin{tabular}{cc}
\hline \hline Verteks & Kopling \\
\hline$P P \gamma$ & $e\left(-i Q_{p} \notin+\mu_{p} \sigma^{\mu v} \varepsilon_{\mu} k_{v}\right)$ \\
$\eta \eta \gamma$ & $-i Q_{\eta}\left(2 q_{\eta}-k\right) \cdot \varepsilon$ \\
\hline \hline
\end{tabular}

\section{Gambar 5. Faktor verteks elektromagnetik}

\section{e. Matriks Transisi}

Amplitudo transisi dari reaksi fotoproduksi dituliskan dalam bentuk:

$\mathcal{M}=$

$\mathcal{M}_{\text {(Born })}+\mathcal{M}_{(\text {Resonan })}+\mathcal{M}_{(\text {Orde yang lebih tinggi })}$

Dalam penelitian ini, perhitungan amplitudo transisi dibatasi sampai pada suku resonans untuk spin $1 / 2$ paritas positif dan negatif. Dimana,

dan

$$
\mathcal{M}_{(\text {born })}=\sum_{i=s, t, u} \mathcal{M}_{i}
$$

$$
\mathcal{M}_{(\text {resonans })}=\sum_{i=s, u} \mathcal{M}_{i}
$$

Matriks transisi pada masing-masing kanal, yaitu:

$$
\begin{gathered}
\mathcal{M}_{s}=\bar{u}_{P}\left(p_{2}\right) g_{\mathrm{\eta} P \mathrm{PP}} \gamma^{5}\left(\frac{k+p_{1}+m_{P}}{\left(k+p_{1}\right)^{2}-m_{P}^{2}}\right)\left(-i Q_{P} \varepsilon\right. \\
\left.+\mu_{P} \sigma^{\mu v} \varepsilon_{\mu} k_{v}\right) \varepsilon_{\mu}(\gamma) u_{p}\left(p_{1}\right)
\end{gathered}
$$

$$
\begin{aligned}
& \mathcal{M}_{u} \\
& =\bar{u}_{P}\left(p_{2}\right)\left(-i Q_{P} \varepsilon\right. \\
& \left.+\mu_{P} \sigma^{\mu v} \varepsilon_{\mu} k_{v}\right) \varepsilon_{\mu}(\gamma)\left(\frac{p_{2}-k+m_{P}}{\left(p_{2}-k\right)^{2}-m_{P}^{2}}\right) g_{\eta \mathrm{PP}} \gamma^{5} u_{p}\left(p_{1}\right)
\end{aligned}
$$

$$
\begin{array}{r}
\mathcal{M}_{t}=\frac{-i e g_{\gamma \eta V} F_{t}^{V}}{m_{\eta}\left(t-m_{V}^{2}\right)} \varepsilon_{\mu \nu \sigma \rho} \bar{u} k^{\mu} \varepsilon^{v}(k-q)^{\sigma}\left[g_{V P P}^{V} \gamma^{\rho}\right. \\
\left.+\frac{g_{V P P}^{t}}{4 m_{p}}\left(q \gamma^{\rho}-\gamma^{\rho}\left(k-p_{1}\right)\right)\right] u
\end{array}
$$

$\mathcal{M}_{s^{*}}^{1 / 2}$

$=\frac{e \mu_{\gamma P P^{*}} g_{\gamma P P^{*}} F_{S}^{P^{*}}}{\left(m_{P}+m_{P^{*}}\right)\left(s-m_{P^{*}}^{2}-i m_{P^{*}} \Gamma_{P^{*}}\right)} \bar{u} \gamma^{5} \Gamma_{5}^{\mathrm{a}}(k$

$\left.+p_{1}+m_{P^{*}}\right) \Gamma_{5}^{\mathrm{a}} \varepsilon k u$

$\mathcal{M}_{u^{*}}^{1 / 2}$

$=\frac{e \mu_{\gamma P P^{*}} g_{\gamma P P^{*}} F_{u}^{P^{*}}}{\left(m_{P}+m_{P^{*}}\right)\left(u-m_{P^{*}}^{2}-i m_{P^{*}} \Gamma_{P^{*}}\right)} \bar{u} \Gamma_{5}^{\mathrm{a}} \varepsilon k(q$

$\left.+p_{1}+m_{P^{*}}\right) \gamma^{5} \Gamma_{5}^{\mathrm{a}} u$

\section{f. Amplitudo CGLN}

Amplitudo CGLN merupakanformalisme perumusan amplitudo proses fotoproduksi yang bersifat invarian Lorentz dan mudah untuk menghitungobservabel reaksielementer [10].

Sehinggapembahasan disini akan dibatasi untuk kasus fotoproduksi danobservabel yang tersedia data eksperimennya.

Berdasarkan referensi [6], maka bentuk metode amplitudo CGLN (ChewGoldberger-Low-Nambu) berupa,

$$
\mathcal{M}=\vec{\jmath} \cdot \vec{\varepsilon}
$$

dengan nilai $\vec{j}$

$$
\begin{array}{r}
\vec{j}=f_{1} \vec{\sigma}+\frac{f_{2}}{|\vec{q}||\vec{k}|}(\vec{\sigma} \cdot \vec{q})(\vec{k} \times \vec{\sigma}) \\
+\frac{f_{3}}{|\vec{q}||\vec{k}|} \vec{\sigma} \cdot \vec{k} \vec{q} \\
+\frac{f_{4}}{|\vec{q}|^{2}} \vec{\sigma} \cdot \vec{q} \vec{q}
\end{array}
$$

dimana $\vec{k}$ adalah momentum awal foton dan $\vec{q}$ adalah momentum akhir dari $\eta$ pada kerangka pusat massa. 
Bentuk umum CGLN akan menjadi

$$
\begin{aligned}
\vec{j} \cdot \vec{\varepsilon}=f_{1} \vec{\sigma} \cdot \vec{\varepsilon}+ & \frac{f_{2}}{|\vec{q}||\vec{k}|}(\vec{\sigma} \cdot \vec{q})(\vec{k} \times \vec{\sigma}) \cdot \vec{\varepsilon} \\
& +\frac{f_{3}}{|\vec{q}||\vec{k}|} \vec{\sigma} \cdot \vec{k} \vec{q} \cdot \vec{\varepsilon} \\
& +\frac{f_{4}}{|\vec{q}|^{2}} \vec{\sigma} \cdot \vec{q} \vec{q} \cdot \vec{\varepsilon}
\end{aligned}
$$

\section{g. Observabel yang Ditinjau}

\section{1) Penampang Lintang Differensial}

Penampang lintang differensial pada kerangka pusat massa, yaitu:

$$
\frac{d \sigma}{d \Omega}=\frac{|\mathcal{M}|^{2}}{64 \pi^{2} s} \frac{|\vec{q}|}{|\vec{k}|}
$$

Kuadrat amplitudo transisi dalam bentuk CGLN, yaitu:

$$
\begin{aligned}
|\mathcal{M}|^{2}=\operatorname{Re}\left\{\left|f_{1}\right|^{2}+\left|f_{2}\right|^{2}-2 \cos \theta f_{2} f_{2}^{*}\right. \\
+\frac{\sin ^{2} \theta}{2}\left[\left|f_{3}\right|^{2}+\left|f_{4}\right|^{2}\right. \\
+2 f_{4} f_{1}^{*}+2 f_{3} f_{2}^{*} \\
\left.\left.+2 \cos \theta f_{4} f_{3}^{*}\right]\right\}
\end{aligned}
$$

\section{2) Polarisasi Foton}

Dengan menggunakan notasi standar dari Babacan [2], polarisasi foton dapat dihitung lewat persamaan:

$$
\sum=\left[\frac{d \sigma}{d \Omega_{\|}}-\frac{d \sigma}{d \Omega_{\perp}}\right] \times\left[\frac{d \sigma}{d \Omega_{\|}}+\frac{d \sigma}{d \Omega_{\perp}}\right]^{-1}
$$

dimana masing-masing adalah penampang lintang differensial yang dipicu oleh polarisasi yang sejajar dan yang tegak lurus terhadap bidang reaksi.

Polarisasi foton dalam bentuk CGLN, yaitu:

$$
\begin{aligned}
\sum=\frac{-|\vec{q}|}{|\vec{k}|} \frac{\sin ^{2} \theta}{2}\left[\left|f_{3}\right|^{2}+\left|f_{4}\right|^{2}\right. \\
+2 \operatorname{Re}\left(f_{2} \cdot f_{3}^{*}+f_{1} \cdot f_{4}^{*}\right. \\
\left.\left.+f_{3} \cdot f_{4}^{*} \cos \theta\right)\right]
\end{aligned}
$$

\section{METODE PENELITIAN}

Penelitian ini dimulai dengan studi literatur mengenai mekanisme produksi untuk menentukan model dan formulasi yang sesuai, menjabarkan amplitudo transisi pada kerangka P.M. ke dalam amplitudo CGLN, yang selanjutnya digunakan untuk menghasilkan data secara teoritis pada proses reaksi fotoproduksi meson $\eta$ pada proton yang akan dikerjakan dengan proses komputasi. Terakhir membandingkan data hasil perhitungan secara teoritis dengan data hasil eksperimen untuk melihat akurasi dari model yang digunakan dalam memproduksi data secara teoritik.

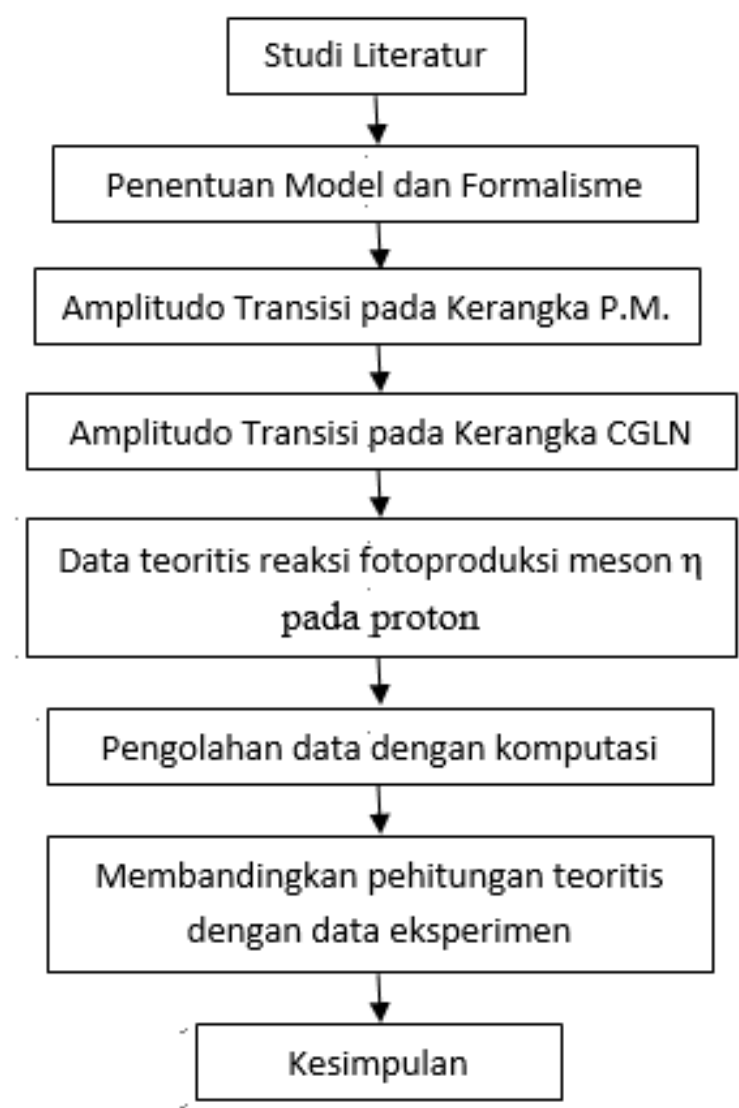

Gambar 6. Metode penelitian

\section{HASIL DAN PEMBAHASAN}

\section{Hasil Penelitian}

Berdasarkan energi ambang foton yang nilainya $706.92 \mathrm{MeV}$, maka energi foton yang digunakan pada perhitungan numerik berkisar $800 \mathrm{MeV}$ hingga $1.200 \mathrm{MeV}$. Hasil perhitungan numerik yang diperoleh 
berdasarkan amplitudo transisi dari suku born dan resonans yang dihitung dengan memanfaatkan diagram Feynman tingkat tiga disajikan sebagai berikut:

\section{A. Penampang Lintang Differensial}

a. Perbandingan Penampang Lintang Differensial pada Energi $875 \mathrm{MeV}$
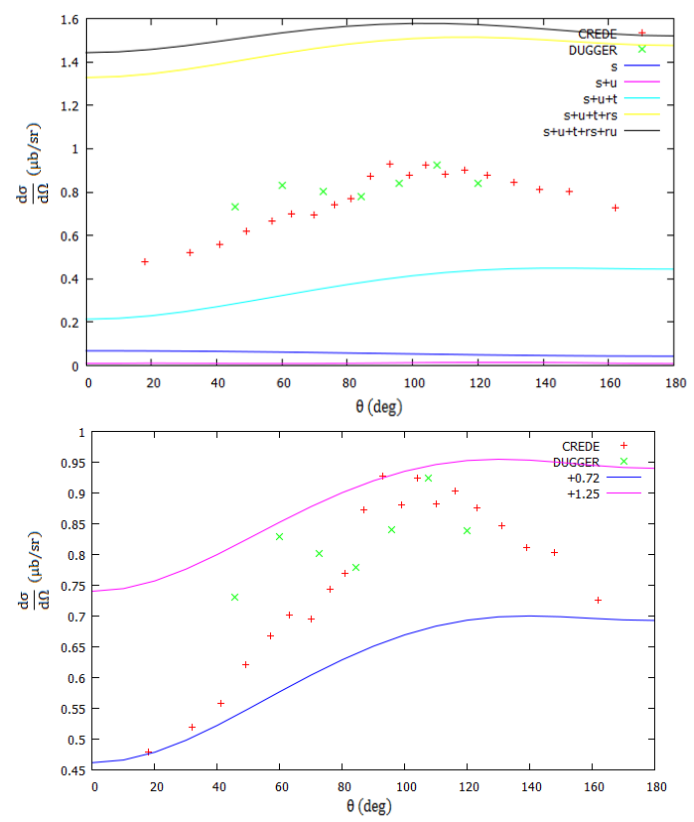

Gambar 7. Perbandingan data numerik dengan data eksperimen pada skala energi $875 \mathrm{MeV}$ dengan penyesuaian konstanta kopling (kanan) dan tanpa penyesuaian konstanta kopling (kiri). Data perbandingan berdasarkan referensi [5] dan [11].

Berdasarkan grafik tersebut, konstanta kopling yang penulis gunakan pada grafik tanpa penyesuaian konstanta kopling berdasarkan referensi [8]. Terlihat bahwa hasil numerik masih jauh dari hasil eksperimen. Pada sudut $0^{\circ}$ hingga $100^{\circ}$ data eksperimen menunjukkan kenaikan nilai penampang lintang differensial, namun pada sudut $100^{\circ}$ hingga $180^{\circ}$ data eksperimen menunjukkan penurunan. Agar hasil numerik bisa mendekati hasil eksperimen, maka dicarilah konstanta kopling resonans yang tepat, yaitu 0.72 dan 1.25 .

\section{b. Perbandingan Penampang Lintang Differensial pada Energi $925 \mathrm{MeV}$}
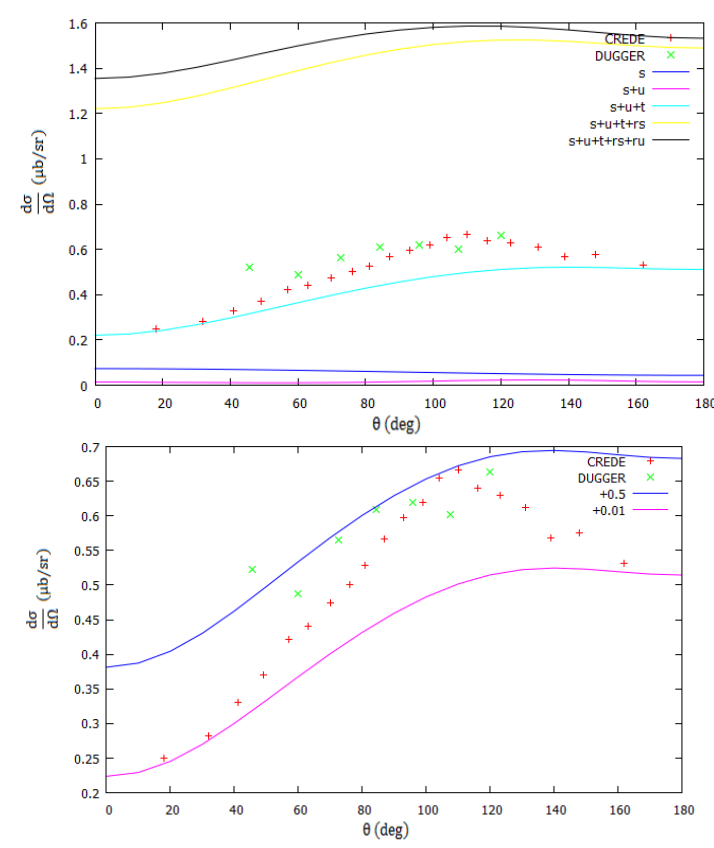

Gambar 8. Perbandingan data numerik dengan data eksperimen pada skala energi $925 \mathrm{MeV}$ dengan penyesuaian konstanta kopling (kanan) dan tanpa penyesuaian konstanta kopling (kiri). Data perbandingan berdasarkan referensi [5] dan [11].

Berdasarkan grafik tersebut, konstanta kopling yang penulis gunakan pada grafik tanpa penyesuaian konstanta kopling berdasarkan referensi [8]. Namun hasil numerik masih jauh dari hasil eksperimen. Pada sudut $0^{\circ}$ hingga $110^{\circ}$ data eksperimen menunjukkan kenaikan nilai penampang lintang differensial, namun pada sudut $110^{\circ}$ hingga $180^{\circ}$ data eksperimen menunjukkan penurunan. Adapun pada perbandingan dengan penyesuaian konstanta kopling yang digunakan yaitu konstanta kopling resonans dengan nilai sebesar 0.5 dan 0.01 . 
c. Perbandingan Penampang Lintang Differensial pada Energi $975 \mathrm{MeV}$
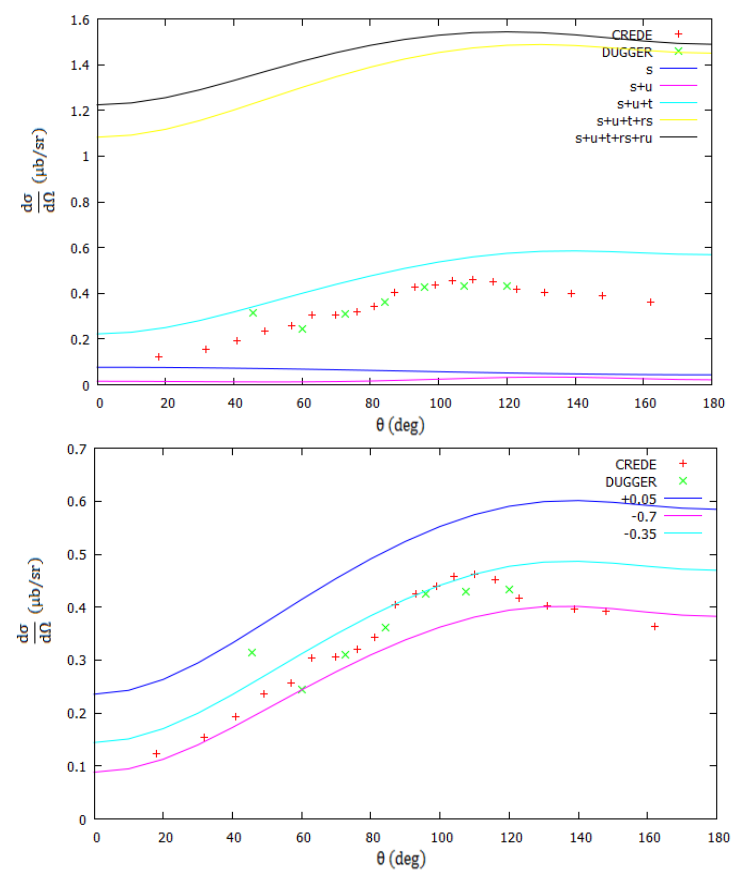

Gambar 9. Perbandingan data numerik dengan data eksperimen pada skala energi $975 \mathrm{MeV}$ dengan penyesuaian konstanta kopling (kanan) dan tanpa penyesuaian konstanta kopling (kiri). Data perbandingan berdasarkan referensi [5] dan [11].

Berdasarkan grafik tersebut, konstanta kopling yang penulis gunakan pada grafik tanpa penyesuaian konstanta kopling berdasarkan referensi [8]. Terlihat bahwa hasil numerik masih jauh dari hasil eksperimen. Pada sudut $0^{\circ}$ hingga $120^{\circ}$ data eksperimen menunjukkan kenaikan nilai penampang lintang dengan hasil yang diikuti data numerik kanal-kanal lainnya selain kanal-s, namun pada sudut $120^{\circ}$ hingga $180^{\circ}$ data eksperimen menunjukkan penurunan nilai penampang lintang differensial. Adapun pada perbandingan dengan penyesuaian konstanta kopling yang digunakan yaitu konstanta kopling resonans dengan nilai sebesar -0.7 dan 0.35 .

\section{d. Perbandingan Penampang Lintang Differensial pada Energi 1.025 MeV}
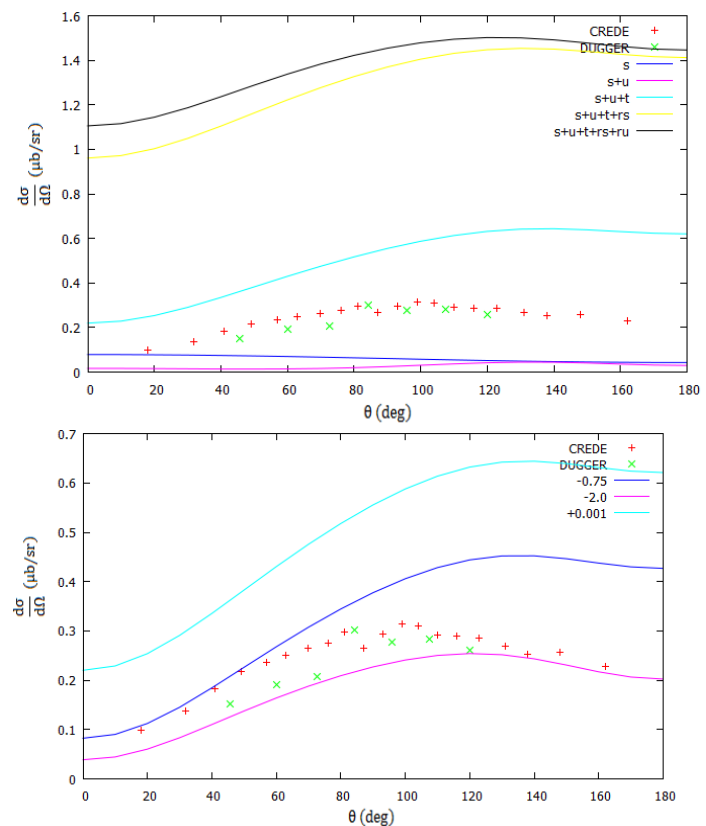

Gambar 10. Perbandingan data numerik dengan data eksperimen pada skala energi 1.025 MeV dengan penyesuaian konstanta kopling (kanan) dan tanpa penyesuaian konstanta kopling (kiri). Data perbandingan berdasarkan referensi [5] dan [11].

Berdasarkan grafik tersebut, konstanta kopling yang penulis gunakan pada grafik tanpa penyesuaian konstanta kopling berdasarkan referensi [8]. Terlihat bahwa hasil numerik masih jauh dari hasil eksperimen. Pada sudut $0^{\circ}$ hingga $120^{\circ}$ data eksperimen menunjukkan kenaikan nilai penampang lintang differensial dengan hasil yang diikuti data numerik kanal-kanal lainnya selain kanal-s, namun pada sudut $120^{\circ}$ hingga $180^{\circ}$ data eksperimen menunjukkan penurunan. Adapun pada perbandingan dengan penyesuaian konstanta kopling yang digunakan yaitu konstanta kopling resonans dengan nilai sebesar -0.75 dan 2.0 . 


\section{B. Polarisasi Foton}

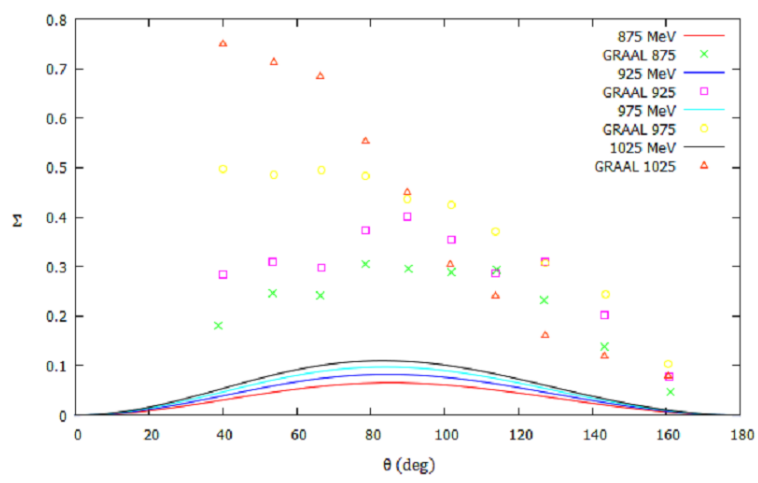

Gambar 11. Perbandingan data numerik reaksi fotoproduksi eta pada proton dengan data eksperimen pada rentang energi 850 1.050 MeV. Data perbandingan berdasarkan referensi [3].

Dari grafik perbandingan tersebut, data numerik dan data eksperimen memiliki pola yang berbeda pada energi $975 \mathrm{MeV}$ dengan trend yang hampir berbeda mulai dari sudut $0^{\circ}$ hingga $120^{\circ}$. Dan terdapat penurunan nilai polarisasi mulai dari sudut $110^{\circ}$ hingga $180^{\circ}$.

\section{Pembahasan}

Berdasarkan grafik yang diperoleh dari penampang lintang differensial dapat dikatakan bahwa model dalam penelitian ini menghasilkan penampang lintang differensial yang backward peaking (puncak pada arah sudut besar), dimana kontribusi kanal-s kecil sedangkan untuk kanal-u terlihat dominan pada arah sudut belakang (backward angle). Hal ini dapat terlihat dengan adanya puncak pada arah sudut belakang (backward peaking) disaat amplitudo kanal u mulai diperhitungkan. Dengan besarnya kontribusi kanal-u maka $\eta$ lebih banyak terhamburkan pada saat di kanal u. Kontribusi resonan sangat mendominasi pola grafik yang dihasilkan sehingga menaikkan besaran penampang lintang differensialnya.

Berdasarkan plot hasil perbandingan data eksperimen dengan hasil perhitungan secara teoritis, diperoleh bahwa hasil data teoritis belum akurat. Dari grafik perbandingan tersebut, data eksperimen dan data numerik secara keseluruhan memiliki data yang berbeda. Data eksperimen menunjukkan grafik memiliki puncak dan lembah sedangkan pada data numerik grafik memiliki sebuah puncak pada sudut besar. Meskipun demikian, tendensinya sudah sesuai.

Model ini belum cukup baik dalam menghasilkan data numerik yang sesuai dengan data eksperimen untuk penampang lintang differensial mulai dari sudut $100^{\circ}$ hingga $180^{\circ}$. Konstanta kopling yang digunakan pada penampang lintang differensial berdasarkan referensi [8], yaitu konstanta kopling pada suku Born 0,47 dan pada suku resonans 2,2. Namun, dicari pula konstanta kopling resonans yang nilainya mendekati eksperimen, yaitu:

Tabel 1: Konstanta kopling pada fotoproduksi $\gamma \mathbf{p} \rightarrow \boldsymbol{\eta} \mathbf{p}$

\begin{tabular}{ccc}
\hline Energi & $\begin{array}{c}\text { Konstanta } \\
\text { kopling suku } \\
\text { born }\end{array}$ & $\begin{array}{c}\text { Konstanta kopling } \\
\text { resonans }\end{array}$ \\
\hline $875 \mathrm{MeV}$ & 0.47 & +1.25 dan +0.72 \\
$925 \mathrm{MeV}$ & 0.47 & +0.5 dan +0.01 \\
$975 \mathrm{MeV}$ & 0.47 & -0.7 dan -0.35 \\
$1025 \mathrm{MeV}$ & 0.47 & -0.75 dan -2.0 \\
\hline
\end{tabular}

Perbandingan data numerik polarisasi foton dengan data eksperimen dari GRAAL diperoleh bahwa pada energi 875 $\mathrm{MeV}$, data numerik menunjukkan kurva yang dengan trend yang mirip dengan data eksperimen. Demikian pula dengan grafik pada energi $925 \mathrm{MeV}$. Namun, pada energi $975 \mathrm{MeV}$, terlihat pola grafik dengan trend yang hampir berbeda antara data numerik dan data eksperimen mulai dari sudut $0^{\circ}$ hingga $120^{\circ}$.

\section{SIMPULAN}

Model dalam penelitian ini menghasilkan penampang lintang differensial yang backward peaking (puncak pada arah sudut besar) dan memiliki kontribusi dari kanal-u 
yang lebih dominan dibandingkan kanal-s, sehingga penampang lintang differensial menjadi backward peaking. Kontribusi resonans sangat mendominasi pada perhitungan penampang lintang differensial dimana resonans lebih berkontribusi dibandingkan dengan kanalkanal born term, walaupun demikian tendensinya sudah sesuai. Secara keseluruhan, model ini belum cukup baik dalam menghasilkan data numerik yang sesuai dengan data eksperimen, sehingga diperlukan studi lanjut untuk mem-fitting data eksperimen dan memasukkan faktor bentuk ke dalam model agar diperoleh nilai-nilai parameter yang ada di dalam model.

\section{UCAPAN TERIMAKASIH}

Terimakasih saya haturkan kepada bapak Dr. Agus Salam selaku dosen Pascasarjana Fisika Murni dan Terapan, Fakultas Matematika dan Ilmu Pengetahuan Alam, Universitas Indonesia atas bimbingan dan koreksinya pada penelitian ini, serta teman-teman fisika teoritik yang telah membagi ilmunya.

\section{DAFTAR PUSTAKA}

[1] Aznauryan, I.G. Resonance Contributions to Photoproduction on Photons Found Using Dispersion Relations and Isobar Model. Phys Rev C 67 015209. (2003).

[2] Babacan, H., danBabacan, T. Associative Photoproduction of Rop-er Resonance and $\omega$ meson. Phys. Rev. C 67, 055208 (2003).

[3] Bartalini. GRAAL Collaboration. Phys. Rev. Lett. 10439-9 (2007).

[4]Dugger, M. Eta (547) and Eta (958) Meson Photoproduction On The Proton. Dissertation. Arizona State University (2001).

[5] Dugger, M. J-LAB Collaboration (Class). Phys. Rev. Lett. 88, 222002 (2002).
[6] G. F. Chew, M. L. Goldberger, F. E. Low, dan Y. Nambu. Phys. Rev. 106, 1345 (1975).

[7] Halzen, F., dan Martin, A. D. Quarks and Leptons: an Introductory Course in Modern Particle Physics. New York: John Wiley and Sons (1984).

[8] K.S. Choi, S. I. Nam, A. Hosaka, dan H. -Ch. Kim. Photoproduction and $N^{*}$ Resonance. Phys. Rev. (2009).

[9] Particle Data Group. Review of Particle Physics, Phys. Rev. D 86, 010001 (2012).

[10] Sumowidagdo, S. FotoproduksiKaonpada Daerah EnergiTinggi. Tesis. Universitas Indonesia. Depok (2001).

[11] V. Crede et al. CB-ELSA Collaboration. Phys. Rev. Lett. 94, 012004 (2005). 